\title{
A História no Currículo Base do Território Catarinense
}

\author{
History in the Base Curriculum in Santa Catarina State
}

\author{
Nucia Alexandra Silva de Oliveira ${ }^{1}$ \\ Helena Alpini Rosa ${ }^{2}$ \\ Denize Aparecida da Silva ${ }^{3}$
}

\section{Resumo}

Este artigo apresenta o processo de escrita do componente curricular História no Currículo Base da Educação Infantil e Ensino Fundamental do Território Catarinense. O objetivo é divulgar alguns dos movimentos que resultaram no texto. Neste sentido, serão apresentados os seguintes acontecimentos e aspectos: o processo de redação do texto (considerando aqui a formação recebida nos seminários organizados pelo Ministério da Educação e o trabalho das redatoras); a revisão realizada com o grupo de profissionais de História; a estrutura apresentada para o Componente Curricular e, por fim, uma discussão sobre os limites e as possibilidades do texto redigido. Intuito da iniciativa é possibilitar a crítica necessária ao documento citado, para que ele possa fazer parte dos processos de ensino e aprendizagem da disciplina.

Palavras-chave: BNCC. Currículo Base do Território Catarinense. Ensino de História.

\begin{abstract}
This article presents the writing process of the History component of the Basic Curriculum for Kindergarten and Elementary School for the state of Santa Catarina, Brazil. The purpose is to publicize some of the movements that resulted in the final text. In this sense, the following events and aspects will be presented: the writing process (considering the training received in seminars organized by the Ministry of Education and the work of writers); the review conducted with the group of History professionals; the structure presented for the Curriculum Component and, lastly, a discussion about the limits and possibilities of the final text. The goal of the initiative is to provide to provide necessary criticism to the document, so that it can be part of the teaching and learning processes of the subject.
\end{abstract}

Keywords: BNCC; Base Curriculum of Santa Catarina State; History Teaching.

\section{Considerações iniciais}

\footnotetext{
${ }^{1}$ Professora no Curso de História e nos Programas de Pós-Graduação em História (PPGH e ProfHistória) na Universidade do Estado de Santa Catarina (UDESC). Pesquisadora no Grupo de Pesquisa Ensino de História Memória e Culturas (UDESC/CNPq), que conta com financiamento da FAPESC por meio de chamadas públicas de apoio a infraestrutura dos grupos de pesquisa da UDESC. Trabalhou como consultora de História no Currículo Base do Território Catarinense entre abril e agosto de 2019. Contato: nucia.oliveira@udesc.br

${ }^{2}$ Professora de História - Técnica da Secretaria de Estado da Educação de Santa Catarina, atuando na Coordenação da Educação do Campo/Indígena e Quilombola, na Gerência de Modalidades, Programas e Projetos Educacionais da Diretoria de Ensino. Trabalhou como redatora de História e hoje trabalha como formadora do Currículo de História na BNCC, representando a rede estadual. Contato: helenaalpini@sed.sc.gov.br

3 Técnica pedagógica na Secretaria Municipal de Educação de Joinville. Redatora, formadora do ensino fundamental do Componente Curricular História/Undime. Contato: denize@joinville.sc.gov.br
} 
Com a aprovação e a homologação da Base Nacional Comum Curricular (BNCC) e a partir do que o próprio documento chamou de "pacto interfederativo”, os estados, os municípios e o Distrito Federal assumiram o compromisso de reelaborar ou de elaborar (visto que muitos municípios não possuem propostas curriculares) seus currículos para a implementação do referido documento. Como é possível ler a seguir:

[...] as redes de ensino e escolas particulares terão diante de si a tarefa de construir currículos, com base nas aprendizagens essenciais estabelecidas na BNCC, passando, assim do plano normativo propositivo para o plano de ação e da gestão currículos que envolve todo o conjunto de decisões e ações definidoras do currículo e de sua dinâmica (BRASIL, 2018, p. 20, grifo nosso).

A redação é bastante objetiva e não deixa dúvidas de que a homologação da BNCC exigia um segundo movimento via estados, Distrito Federal e municípios. Um processo, como se vê, de grande impacto, sobretudo considerando a questão explicitada no grifo que fizemos ao texto: “aprendizagens estabelecidas na BNCC”. Ou seja, trata-se de dizer que este documento passa a ser um orientador do que se espera com o processo de ensino, considerando uma universalização de oportunidades e vivências para os/as estudantes brasileiros/as. Algo aliás, bastante difícil de se alcançar, considerando as conhecidas desigualdades existentes em nosso país!

No estado de Santa Catarina, o processo de produção do currículo teve início em 2015, com a criação da Comissão Executiva Estadual da BNCC e, depois, em 2016, com a fundação do Comitê Executivo, em regime de colaboração, formado pela Secretaria de Estado da Educação (SED), pelo Conselho Estadual de Educação (CEE), pela União dos Dirigentes Municipais de Educação de Santa Catarina (Undime) e pela União dos Conselhos Municipais de Educação (Uncme) (SANTA CATARINA, 2019, p. 11). A opção pelo chamado "regime de colaboração” está prevista na própria BNCC e, ainda, no Plano Nacional de Educação (PNE), através da Lei 13.005/2014.

O processo de preparação e escrita, no entanto, só passou a ocorrer a partir do ano de 2018, com a aprovação da BNCC. O trabalho teve início com a realização de encontros de formação para os redatores selecionados pelos setores envolvidos no regime de colaboração e com a realização de consultas públicas para a escrita do texto. Nesse processo, algumas datas e acontecimentos foram importantes, tais como, o chamado dia D - para discussão da BNCC nas escolas. Vale dizer que o Ministério da Educação (MEC) determinou a data de 6/3/2018 para esse evento, que, em Santa Catarina, ocorreu em 20/3/2018. O dia D foi um momento muito importante, pois cada município desenvolveu estratégias no sentido de estudar e entender as 
mudanças e os impactos que a implementação BNCC representava para as práticas pedagógicas. Na realidade, em algumas escolas se registrou uma certa resistência à nova legislação; muitos professores sentiram dificuldades quanto à nova proposta. Tais dificuldades, em geral, estavam relacionadas a questões referentes aos objetos de conhecimento e a habilidades que eles entendiam ser incoerentes com o tempo/números de aulas.

Já em 2019, ocorreu a contratação de consultores para a finalização do trabalho e a realização do processo de revisão do texto em um seminário realizado com participação de mais de 400 profissionais de educação do estado. Nesse ano, também foram realizados mais dois seminários com vistas a organizar maneiras de multiplicar as discussões sobre o documento base nos diferentes municípios catarinenses. Falaremos mais sobre esses acontecimentos no decorrer do texto.

Assim, o Currículo Base da Educação Infantil e Ensino Fundamental do Território Catarinense teve sua implantação aprovada pelo Conselho Estadual de Educação através da Resolução CEE/SC nº. 070, de 7 junho de 2019. Sua homologação se deu a partir da aprovação do governo do estado. Tal medida representa, ao mesmo tempo, o encerramento de um ciclo e o início de outro, ambos notadamente importantes. A resolução representa o fechamento de um ciclo de estudo e escrita do texto. Por outro lado, indica o início de outro processo, que é justamente o da implementação deste documento como referencial para o trabalho nas escolas em todo o estado. Tal processo se efetuará por meio de ações de formação e monitoramento, desenvolvidas com as regionais, com as secretarias de Educação e com as associações dos municípios.

O presente texto tem por propósito central narrar o processo de redação do componente curricular História dentro do referido documento. Ou, talvez seja melhor dizer, desejamos contar alguns momentos desse movimento, visto que contar uma história é fazer opções e essas, por vezes, podem incidir em lacunas ou esquecimentos. Certamente, não entendemos propor em tal narrativa a "verdade" sobre os fatos vividos. Assim, assumimos que narramos parte desse processo, buscando dar visibilidade às nossas experiências como redatoras e consultoras de um texto finalizado a partir do olhar de muitos profissionais relacionados à disciplina, como explicaremos mais à frente. Nossa intenção, ao narrar tal processo, é propor o documento ao debate de professoras e professores de História, para que, no cotidiano escolar, ele possa ser amplamente vivido e, portanto, revisado e atualizado. O exercício de observar e avaliar a nova dinâmica proposta é essencial, pois foi definido um tempo de "validade” de cinco anos para a BNCC. Ou seja, em 2024 o documento deverá ser revisto e, consequentemente, modificado 
naquilo que os entes envolvidos no processo julgarem necessário. Vale destacar que, para realizar as mudanças, está previsto um processo de participação popular, envolvendo o poder público e a sociedade civil. Possivelmente, igual processo será necessário para o Currículo do Território Catarinense. Nosso papel, como professores e professoras de História, é vital nessa dinâmica, sendo, portanto, não apenas necessário, como desejável que tanto a proposta da BNCC quanto a do Currículo Base do Território Catarinense sejam amplamente discutidas e estudadas.

Neste sentido, no presente artigo serão apresentados os seguintes acontecimentos e aspectos: o processo de redação do texto (considerando aqui a formação recebida nos seminários organizados pelo Ministério da Educação e o trabalho das redatoras); a revisão realizada com o grupo de profissionais de História e da consultora; a estrutura apresentada para o Componente Curricular e, por fim, uma discussão sobre os limites e as possibilidades do texto redigido.

Entendemos, no entanto, não ser possível tratar de parte do texto sem considerar seu todo. Assim, faremos também algumas considerações sobre os princípios que norteiam o Currículo Base do Território Catarinense frente ao que propõe a BNCC. Entendemos ser importante conhecer tal movimento, considerando que a escrita de um documento curricular é sempre um momento de grande tensão quando decisões sobre o que fará parte ou não do documento envolvem, antes de tudo, questões políticas.

\section{A BNCC e o currículo base do território catarinense: aproximações e especificidades}

A produção de um currículo é uma interferência direta no processo educativo. Sobre isso não restam dúvidas, embora consideremos que conceituar o termo “currículo” não seja uma tarefa fácil. Não desejamos aqui entrar na discussão conceitual sobre o termo currículo; o que nos interessa de modo mais direto é apontar para o fato de que, ao construir um currículo, se fazem escolhas. Decisões aliás, que nem sempre representam a vontade da maioria, visto que em alguns momentos extrapolam ou até ignoram o espaço escolar e suas vivências, para antes serem decisões políticas. Como nos lembra a historiadora Kátia Abud:

Os currículos e programas constituem o instrumento mais poderoso de intervenção do Estado no ensino, o que significa sua interferência, em última instância, na formação da clientela escolar para o exercício da cidadania, no sentido que interessa aos grupos dominantes. [...] Nesse processo, o discurso do poder se pronuncia sobre a educação e define seu sentido, forma, finalidade e conteúdo e estabelece, sobre cada disciplina, o controle da informação a ser transmitida e da formação pretendida (ABUD, 2006, p. 28). 
É preciso considerar, portanto, que, além de um “rol de conteúdos”, ou ainda de ordenamentos disciplinares, quando folheamos as páginas de um currículo e localizamos as intenções pensadas para o processo de ensino temos nelas mais do que objetivos de aprendizagem. Como bem exposto pela pesquisadora referenciada, um currículo é um projeto/processo de intervenção sobre a Educação e sobre os sujeitos presentes nos espaços escolares!

Nos últimos tempos, o estabelecimento da BNCC retomou as discussões sobre currículo e seu papel na Educação, bem como colocou em questão mais uma vez quais são as orientações do Estado frente ao processo educativo. Nesse contexto, a opção de currículo que orienta para o desenvolvimento de "competências" como elemento norteador do processo de ensino tem gerado dúvidas e polêmicas, sobretudo pelo pouco esclarecimento que se deu frente a esse conceito. Na BNCC, tem-se que:

[...] competência é definida como a mobilização de conhecimento (conceitos e procedimentos), habilidades (práticas cognitivas e socioemotivas), atitudes e valores para resolver demandas complexas da vida cotidiana, do pleno exercício da cidadania e do mundo do trabalho (BRASIL, 2018, p. 8).

Pelo exposto e de acordo com o referido documento, o processo de ensino deve ser pensado para o desenvolvimento de competências, sendo estas alçadas através de diferentes conhecimentos, habilidades, atitudes ou valores (BRASIL, 2018. p. 13). A opção por esses conceitos, no entanto, não é justificada no texto em questão, sobretudo porque não apresenta referências teórico-metodológicos sobre eles. Na verdade, a explicação para essa opção, ainda de acordo com o texto da BNCC, se dá para cumprimento de acordos feitos pelo Brasil com Organização das Nações Unidas para a Educação, a Ciência e a Tecnologia (Unesco), com vistas no enfoque de avaliações internacionais, como as do Programa Internacional de Avaliação de Alunos (Pisa - Brasil, 2019, p. 13). Ou seja, antes de ser um projeto para a educação brasileira, esse documento se parece mais com uma proposta de "adequação" dos nossos currículos a políticas externas. Um aspecto certamente bastante complexo e sobre o qual precisaremos nos debruçar nos movimentos que se seguem - de vivência efetiva da BNCC nas escolas de todo o país. Afinal: qual o impacto dessa “adequação” a políticas externas para a educação básica no Brasil? O que significa, de fato, optar por termos como habilidade e competências e o que têm eles em comum com o que entendemos por qualificação dos processos de ensino e aprendizagem? 
Esse tipo de discussão extrapola os limites e intenções do presente artigo, mas é impossível não mencioná-los, considerando ser necessário que os conceitos estruturais da BNCC (competência e habilidade) sejam mais debatidos e mais bem compreendidos por todos/as nós, especialmente considerando sua centralidade no documento em questão, além de todos os movimentos que dele derivam: materiais didáticos, avaliações, projetos de formação docente, etc.

Vale dizer que chamamos a atenção para tais termos, considerando constarem também no Currículo Base do Território Catarinense; afinal, esse texto tem como referência o texto nacional, como é possível observar nos trechos a seguir, retirados da apresentação do documento catarinense:

Na Educação Infantil, mantivemos a organização prevista na BNCC, de modo a respeitar os Direitos à aprendizagem e ao Desenvolvimento e propor dois organizadores: campos de experiência e faixa etária [...] No Ensino Fundamental, também optamos por uma organização por áreas do conhecimento. Em cada uma, estão definidas as competências por área e as do componente curricular (SANTA CATARINA, 2019, p. 18-19).

Cabe acrescentar, no entanto, que, além desse “diálogo” com a BNCC, houve um movimento no sentido de buscar uma referência que desse conta de também dialogar com a história da educação no estado, respeitando especialmente o percurso vivido através da Proposta Curricular de Santa Catarina (PC/SC) e dos documentos curriculares dos sistemas municipais.

Na introdução do Documento Base, estes elementos são apresentados aos leitores: "Nas escolhas que foram feitas neste texto, valorizamos dois princípios fundamentais, quais sejam: o da educação integral e o percurso formativo" (CURRÍCULO BASE, 2019, p. 14, grifos nossos). A respeito da educação integral, enfatiza-se que se trata de atender ao que está disposto na Constituição Federal de 1988, na Lei de Diretrizes e Bases da Educação (1996), no Plano Nacional de Educação (2014) e, mesmo, na própria BNCC. É dito, ainda, que o conceito de educação integral, nesse documento, será o mesmo já apresentado na Proposta Curricular de Santa Catarina em 2014, a saber: "[...] uma estratégia histórica que visa desenvolver percursos formativos mais integrados, complexos e completos, que considerem a educabilidade humana em sua múltipla dimensionalidade" (SANTA CATARINA, 2014, p. 26).

Pelo exposto na citação e também na reflexão que a acompanha no Currículo Base, entende-se que a ideia central para a sua construção foi amparada no entendimento de que a educação deve ser pensada de modo a integrar as diferentes áreas do conhecimento, sem que se compartimentem. E, ainda, que o processo de educação respeite os indivíduos em suas 
especificidades. Vale citar o compromisso assumido no texto em prol de uma educação que forme estudantes para a emancipação em seu processo de conhecimento.

[...] assume e alicerça-se no princípio da educação integral, por entender que, por meio dela, promover-se-á uma formação que visa à cidadania, à emancipação e à liberdade como processos ativos e críticos que possibilitam ao estudante o pleno desenvolvimento e a apropriação do conhecimento e da cultura historicamente construídos, bem como o protagonismo de seu percurso formativo (SANTA CATARINA, 2019, p. 15, grifo nosso).

Na reflexão sobre a primazia da educação integral, o texto traz a ideia de percurso formativo como um movimento central desse processo. O conceito propõe uma orientação segundo a qual “a elaboração de conhecimentos vai se tornando complexa de maneira orgânica e progressiva” (SANTA CATARINA, 2019, p. 16). Encontramos aqui, mais uma vez, a inspiração de tal princípio na Proposta Curricular, seja pela referência a esse texto, quanto pela utilização da imagem do conhecimento como uma espiral (Fig. 1). “A sugestão é que se considere o desenvolvimento em espiral, partindo das experiências para a elaboração conceitual, por possibilitar a sucessão crescente e a garantia ininterrupta de aprendizagem e de desenvolvimento" (SANTA CATARINA, 2019, p. 16).

Figura 1 - Processo de elaboração conceitual em espiral

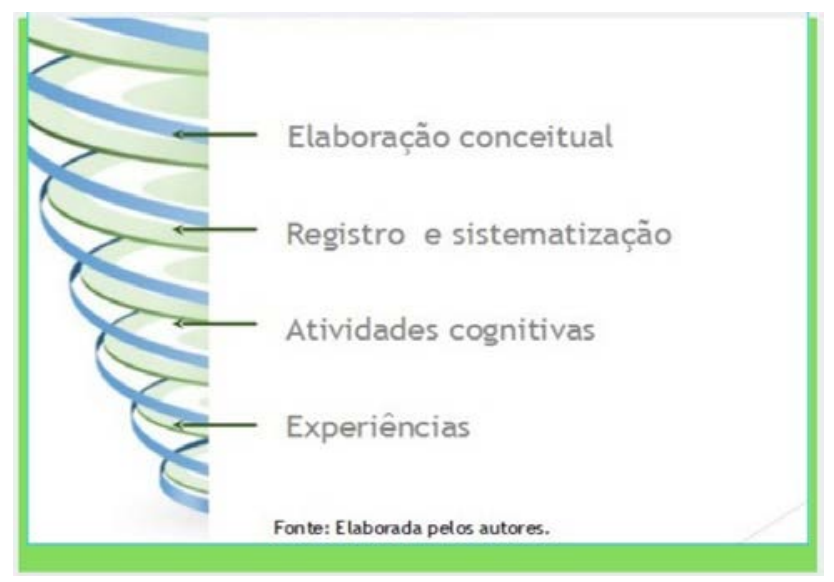

Fonte: Autores - Santa Catarina, 2019, p. 16.

Ainda apontando especificidades no texto catarinense, cabe acrescentar que no processo de trabalho se optou por dar destaque a duas questões que na BNCC não apresentam tanta visibilidade: à diversidade, como princípio formativo e ao processo de alfabetização. Como é possível observar, esses dois temas ocupam parte significativa no texto, com discussões específicas diversas. Percorrendo o sumário, encontramos o capítulo: “A diversidade como princípio formativo na educação básica”, subdividido nos seguintes subcapítulos: Educação Ambiental Formal; Educação para as Relações Étnico-raciais; Educação de Pessoas Jovens, 
Adultas e Idosas (EJA); Educação Escolar Quilombola; Educação Escolar Indígena; Educação do Campo e Educação Especial, na perspectiva da educação inclusiva.

Pelo exposto, compreende-se que a centralidade desses elementos se deve ao entendimento da diversidade como elemento essencial do princípio formativo e se fundamenta nos processos de ensino e aprendizagem. Além disso, por privilegiarem o educar na alteridade; a consciência política e histórica da diversidade; o reconhecimento, a valorização da diferença e o fortalecimento das identidades; a sustentabilidade socioambiental; o pluralismo de ideias e de concepções pedagógicas; a laicidade do Estado e da escola pública catarinense e a igualdade de direitos para acesso, permanência e aprendizagem na escola para todos os estudantes, independentemente de suas especificidades humanas.

Nessa mesma abordagem, é importante dizer que também aparecem, ao longo do texto, temas contemporâneos, como: direitos da criança e do adolescente; educação para o trânsito; educação ambiental; educação alimentar; processo de envelhecimento; respeito ao idoso e sua valorização; educação em direitos humanos; educação em relações étnico-raciais; ensino de história e cultura afro-brasileira, africana e indígena; saúde, vida familiar e social; educação para o consumo; educação financeira e fiscal; trabalho, ciência, tecnologia e diversidade cultural. Ainda de acordo com o texto, tais temáticas devem ser trabalhadas observando-se aspectos da vida local, regional e global, assim como necessitam estar previstas nos currículos e nos projetos político-pedagógicos, possibilitando o trabalho de forma transversal e integradora.

Muitas outras questões poderiam ser abordadas de modo a caracterizar o Currículo do Território Catarinense em suas aproximações e especificidades frente à BNCC, proposta do presente estudo. Esse processo, porém, poderia alongar muito nossa discussão. Para finalizar o item, cabe esclarecer entender-se ser possível caracterizar o texto curricular como um documento datado e influenciado pelo contexto político em que vivemos neste ano de 2019, e sua relação com o de anos anteriores, quando a própria BNCC foi escrita, alinhando-se às políticas demandadas pelos organismos internacionais aqui já mencionados. Assim, o ordenamento curricular, de acordo com os conceitos de competência e habilidade, impõe-se como algo sobre o qual precisaremos estar atentos/as nos próximos tempos, considerando a necessidade de revisão que já aparece indicada na lei.

Também é possível defini-lo como um texto plural e democrático, visto ter sido escrito a partir de tantos olhares e intenções de diferentes profissionais. Não temos um currículo ideal ou perfeito. Longe disso! Como os consultores de currículo escreveram na parte final de sua 
apresentação, trata-se de um texto que demanda utilização ativa e crítica dos professores e das professoras para que as devidas apropriações o façam possível.

\section{O texto de História: redação e estrutura}

\section{Redação do texto: um longo e difícil processo}

A definição das equipes responsáveis por cada um dos componentes curriculares no Currículo Base de Santa Catarina se deu através de acordos realizados entre os diferentes setores, organizados em regime de cooperação, conforme já referido. Essas equipes compostas, na maioria, por dupla de redatores, mas, em alguns casos, por três -contaram com profissionais (oriundos/as de diferentes municípios catarinenses) representantes da Undime e da Secretaria Estadual de Educação. No caso da História, um nome foi um indicado pela Undime; outro, pela SED.

O processo de trabalho teve início em fevereiro de 2018, quando foi realizado um encontro em Florianópolis com todo o grupo envolvido no trabalho.

No final do mês de março de 2018 (de 26 a 28), foi realizado o I Encontro de Formação para o Programa de Apoio à Implementação da Base Nacional Comum Curricular - Educação Infantil e Ensino Fundamental. Esse evento aconteceu em Brasília/DF. Nele estavam presentes os redatores, coordenadores e formadores dos estados e do Distrito Federal para compreender o documento da BNCC e receber orientações para os estados elaborarem seus próprios currículos. Este processo foi realizado obedecendo ao mesmo sistema de pactuação SEDs e Undime. No I Encontro, a formação recebida foi organizada pelo MEC e a profa. Janice Theodoro foi a palestrante. Nos demais (II e III Encontro de Formação), técnicos da Fundação Lemann e Reúna ${ }^{i}$ passaram a fazer parte da equipe de formação.

A escrita da primeira versão do currículo, chamada "versão 0”, foi um processo desafiador e complexo, apesar do entendimento geral sobre exigências, possibilidades e pressupostos legais. Os documentos determinam que o currículo seja composto por uma parte comum e uma parte diversificada; no entanto, essas partes não podem estar dispostas separadamente ou de forma desconexa. A BNCC estabelece a parte comum, que deverá compor todos os currículos escolares de aplicação no país; já a parte diversificada restringe-se aos conteúdos de ordem regional e local. Uma e outra parte devem ser trabalhadas de maneira articulada e complementar, assegurando o acesso e a democratização do conhecimento a todos. 
No curso de formação, a preparação teve por objetivo preparar os participantes a realizar a tarefa de pensar a "parte diversificada". Assim, todos se sentiram desafiados a propor um currículo que oferecesse espaço à parte comum, assim como oferecesse espaço ao diálogo (de forma orgânica, integrada e contextualizada) à parte diversificada. Isto significa que os municípios e as escolas de Santa Catarina poderão usar como referência o Currículo do Território Catarinense sem suprimir suas especificidades, as características com as quais se identificam.

Seguindo as orientações recebidas em Brasília e os encaminhamentos definidos nas reuniões, os da equipe de Santa Catarina optamos (a princípio, todo o grupo) por organizar o texto em quadros e colunas. A primeira coluna traria as Unidades Temáticas; a segunda, os Objetos de Conhecimento; a terceira, as "Habilidades" - todas compostas a partir do modelo proposto pela BNCC. A quarta coluna, por sua vez, seria a parte específica do documento catarinense, a ser trabalhada por suas próprias equipes. Esta coluna receberia os “Conteúdos”. Para caracterizar o componente curricular História, a preocupação foi marcar conhecimentos relevantes para a história de Santa Catarina e garantir também que os municípios pudessem fazer constar do currículo suas histórias. Convém lembrar que a orientação era arranjar os conteúdos de maneira que atendessem ao desenvolvimento das habilidades determinadas para cada ano.

Devemos dizer que, para a maioria dos componentes, a opção de alinhamento de colunas e a criação da coluna “conteúdos” foi uma ação “adequada”. No entanto, em relação à História, esta acabou por se tornar uma tarefa muito difícil, em razão da grande diferença na maneira utilizada pela BNCC em apresentar os objetos de conhecimento e as habilidades para os Anos Iniciais e os Anos Finais do Ensino Fundamental. Isso porque, para os Anos Iniciais, a base utiliza objetos de conhecimento e habilidades que entendemos serem mais “conceituais”, enquanto que para os Anos Finais o que se tem é uma abordagem mais “conteudista”.

Uma questão importante, e que deve ser reforçada, é que no movimento de escrita desta quarta coluna houve um encaminhamento aos Anos Iniciais e outro, aos Anos Finais, por conta das especificidades presentes na própria BNCC. Ou seja, uma vez que os objetos de conhecimento não careciam de conteúdos para complementar os Anos Iniciais, decidimos propor na coluna em questão o subtítulo “Orientações metodológicas”, pela necessidade, assim o entendemos, de ajudar a otimizar as práticas pedagógicas nesta etapa.

A questão foi explicada no texto introdutório do Componente História: 
[...] na BNCC, o componente curricular de História está distribuído a partir de duas óticas diferentes: uma para os anos iniciais e outra, para os anos finais. Essa característica é percebida na maneira como foram elaborados e definidos os objetos de conhecimento e as habilidades (SANTA CATARINA, 2019, p. 421,422, versão on line).

Da mesma forma, procuramos explicar como esta questão foi "resolvida” pela equipe de redação no momento de organizar a escrita e eleger o que passaria a constituir a coluna em construção. A respeito do trabalho com a coluna dos Anos Iniciais, assim está explicado:

O trabalho realizado para a escrita do currículo base para o território catarinense foi feito no sentido de apresentar considerações que aparecem como desdobramentos dos objetos de conhecimento para o desenvolvimento das habilidades. Assim [foi] construído e organizado o texto na 4 a coluna do quadro [...] "conversar" com os objetos de conhecimentos e as habilidades originalmente apresentadas no texto da BNCC. Essa coluna não apresenta linhas para que sejam compreendidas como questões que podem/devem ser movimentadas sempre que os/as professores/as e o Projeto Político Pedagógico sentirem a necessidade de tal movimentação pedagógica (SANTA CATARINA, 2019, p. 421-422, versão on line).

Por sua vez, considerando o que propôs a BNCC para os Anos Finais - de que nela os objetos de conhecimento e as habilidades fossem caracterizados por uma “ordenação factual”:

[...] a opção do grupo de trabalho foi pensar as abordagens também nessa ordenação cronológica. Assim, a coluna foi construída estabelecendo o que chamamos de desdobramento ou abordagens de/aos conteúdos. Diante da necessidade de pensar sobre habilidades construídas originariamente em função dos conteúdos, foram listados desdobramentos e/ou inseridos temas diretamente relacionados ao estado de Santa Catarina, no passado e no presente. [...] a opção do grupo foi optar por estruturar linhas mais próximas às habilidades, sendo importante lembrar, no entanto, que essa separação não significa necessariamente uma segmentação dos conteúdos; afinal, eles precisam ser operacionalizados de forma relacional e dialógica (SANTA CATARINA, 2019, pp. 421,422, versão on line).

Em junho de 2018, o documento preliminar foi submetido a consulta pública via internet (nos sites da SED e Undime) para permitir aos profissionais entrar em contato com o documento, fazer questionamentos, expor suas opiniões e contribuir com sugestões de mudanças no texto. O texto de História recebeu 11 sugestões de diferentes regiões do estado. Foram poucas, mas significativas e importantes para a reescrita do documento, tendo sido, portanto, incorporadas ao texto. Vale dizer que tais contribuições, em sua maioria, foram acatadas no sentido de acrescentar ou suprimir conteúdos nos textos relativos aos Anos Finais e também para sugerir questões conceituais nas questões dos povos indígenas e das comunidades tradicionais. 
Ainda em 2018, nos dias 21 e 22 de agosto, ocorreu em Brasília o II Encontro de Formação para o Programa de Apoio à Implementação da Base Nacional Comum Curricular Educação Infantil e Ensino Fundamental. A pauta desse encontro foi pensada no sentido de oferecer suporte técnico às equipes dos estados para finalizarem e iniciarem a implementação do currículo em seus territórios. Aqui em Santa Catarina, o encontro de trabalho para estruturar o texto ocorreu nos dias 22 e 23 de outubro, em Joinville. Nesse momento, foi organizada uma versão preliminar do texto a ser avaliado pelo Conselho Estadual de Educação. No final do ano, nos dias 12, 13 e 14 de dezembro, aconteceu em Brasília o III Encontro Formativo do Programa de Apoio à Implementação da BNCC- PROBNCC - Educação Infantil e Ensino Fundamental. No estado, o ano se encerrou com o texto em processo de avaliação pelo CEE.

O ano de 2019 foi de finalização da redação. Como já mencionado, foi nesse ano que os consultores passaram a fazer parte do processo de trabalho. A contratação dos consultores de área aconteceu no momento de finalização do texto e de realização dos seminários previstos para a sua discussão e para as ações de estudo e de sua disseminação. É fundamental informar que a finalização (e a aprovação) do texto de História contou não apenas com a equipe de redação e respectiva consultoria, mas a partir do olhar de um grupo formado por 35 profissionais ${ }^{\text {ii }}$.

O processo de trabalho aconteceu entre os dias 15 e 17 de abril, na cidade de São José, no I Seminário para a Construção do Currículo Base da Educação Infantil e Ensino Fundamental do Território Catarinense. Nesse encontro, foi organizada uma dinâmica para debate do texto redigido, item por item, obedecendo a um ritual de leitura, crítica, escrita e reescrita. Contar a história desse movimento tão intenso não é simples, pois, dificilmente uma “ata” poderia contemplar o volume de acordos e desacordos de um debate desse porte. O que podemos dizer é que se tratou de um movimento difícil, sobretudo considerando a questão do "volume” de conteúdos apresentados na BNCC, que, consequentemente, repercutiria no Currículo Catarinense. Se houve unanimidade nesse processo de trabalho, ela pode ser descrita pela indagação a respeito do formato a dar a um currículo de História. Afinal, como eleger temáticas sem relegar outras igualmente importantes? Que narrativas contemplar e por quê? Estas são, aliás, questões pulsantes no universo de professoras e professores de História que, como dito, estiveram presentes em todo o processo de escrita do texto.

Mas, se falamos aqui em redação de texto, devemos também falar um pouco mais sobre como foi organizado o trabalho de sua revisão. Neste sentido, é preciso dizer que, entre os dias 15 e 17 de abril do ano de 2019, o "grupo de história” se reuniu para discutir o texto que foi 
redigido e submetido a consulta pública como mencionado. Uma leitura prévia foi a tarefa demandada a esses profissionais para que no seminário o trabalho pudesse avançar mais rapidamente, considerando o volume de trabalho e o tempo previsto para ele. Assim, o primeiro movimento do trabalho foi explicitar o processo de escrita do texto e o formato pelo qual se optou. Nesse momento, conversamos muito sobre a própria BNCC e o processo de sua escrita. Feito este trabalho de compreensão do formato, passamos a discutir se ele sofreria ou não alteração, uma vez que a coordenação geral sempre reiterou que esse documento precisaria ser consolidado com o grupo de trabalho. A questão sobre o texto apresentado foi mesmo a grande quantidade de conteúdos presentes na BNCC e, consequentemente, na quarta coluna de nosso texto. Sob este aspecto, um conflito se estabeleceu: de um lado, a constatação e a preocupação diante do volume apresentado; de outro, uma dúvida gigantesca sobre o formato a ser adotado para modificar o modelo que se estabelecia. Ficamos diante de um grande impasse, sobretudo diante da obrigatória conexão entre os dois documentos; assim, a opção para finalizar o texto foi mantê-lo como havia sido pensado pela equipe de redação, procurando assegurar temáticas relativas à História de Santa Catarina ou, ainda, indicando possibilidades de abordagens aos conteúdos listados.

A seguir, algumas das características presentes no texto.

\section{Caraterísticas do texto de História}

Como apontamos no item anterior, a redação do texto do Componente Curricular de História esteve muito atrelada à da BNCC. Assim, é impossível caracterizar o documento catarinense sem nos referir também ao formato do texto nacional.

A escrita do texto relativo à História na BNCC foi um processo que trouxe à tona importantes questões sobre a estruturação e a escolha dos assuntos que fariam ou não parte dos currículos. Christian Laville definiu bem o processo de escrita curricular como uma "guerra de narrativas” (1999). O intenso debate de que participamos nos anos de 2015 e 2016 a respeito da História na BNCC foi justamente esse: de confronto! Como sabemos, a primeira versão foi duramente criticada - por profissionais da área de História, por alguns setores da mídia e também por parte da sociedade. A questão em debate foi o abandono da tradição da história linear e de uma divisão quadripartite da História. Conforme avaliou a historiadora Flavia Caimi, “[...] a proposta então apresentada mostrava avanços ao romper com modelos explicativos, pautados num código disciplinar centenário, que já não responde às demandas e desafios que se apresentam à sociedade brasileira” (CAIMI, 2016, p. 90). O resultado das críticas a essa 
primeira versão da BNCC é conhecido - o texto foi totalmente reescrito e, ao contrário de outros componentes curriculares que tiveram seus conteúdos discutidos e amadurecidos no processo de escrita, caracteriza-se por ter sido entregue pronto, em sua versão final. Longe de polêmicas, a versão aprovada, traz como característica central o que se poderia definir como “tradição disciplinar”. Ou seja, é um texto que respeita o cânone do código disciplinar e elenca "Unidades temáticas, Objetos de Conhecimento e Habilidades”, construídos nessa perspectiva.

Como temos aqui apontado em diferentes momentos, o processo de aproximação do Currículo Catarinense com a BNCC legou a esse documento também essa característica. Assim, quando se explora o percurso formativo dos Anos Iniciais aos Anos Finais em busca de conteúdos a ensinar e a aprender, a sensação é de que temos no documento toda a História da humanidade a ser ensinada, ou pelo menos boa parte dela! O que sabemos é bastante complexo!

Se considerarmos que o documento tem essa marca - não há como negar, temos sim um currículo de conteúdos -, devemos notar que o caminho que segue o da tradição não significa que o texto (podemos aqui falar tanto da BNCC quanto do Currículo Catarinense) traga para o processo de ensino e aprendizagem de História outras tradições da disciplina - como a memorização, o estudo do passado pelo passado ou, ainda, a ênfase na história dos grandes homens e seus feitos.

Vale lembrar que o componente História é apresentado na BNCC partindo do pressuposto de que o conhecimento histórico é uma forma de pensar, uma forma de indagar sobre as coisas do passado e do presente, de construir explicações, de desvendar significados e de interpretar o mundo ao longo do tempo e do espaço (BRASIL. 2016, p. 395). Assim, propõe Competências e Habilidades por possibilitarem analisar e compreender os significados de diferentes lugares, objetos, circunstâncias, temporalidades, movimentos de pessoas e saberes.

Outra questão importante é a de se dever buscar entre educadores e educandos a formação da atitude historiadora, construída a partir do desenvolvimento de processos como: identificação, comparação, contextualização, interpretação e análise (BRASIL, 2018, p. 396, grifos nossos). Ou seja, trata-se de partir da ideia de que ensinar História é também possibilitar aos estudantes a compreensão contextualizada dos acontecimentos históricos, de forma a elaborar questionamentos, hipóteses e argumentos.

Considerando que a BNCC estabelece como relevante o estudo da História partindo das referenciais “Eu, Outro, Nós”, o texto catarinense também procurou demarcar espaço para conteúdos que possam estabelecer diálogos a partir dessa relação. Assim, temos, ao longo do texto, diferentes conteúdos propostos, elaborados no sentido de atender a habilidades que 
contemplam esta premissa, que é a de possibilitar aos estudantes o conhecimento de si mesmos, para, depois, o do outro, reconhecendo esses conhecimentos em diferentes espaços e tempos.

A preocupação no processo de escrita deste componente foi a de dar ênfase a temas específicos, aos conteúdos determinados legalmente, tais como: educação para os direitos humanos, para o desenvolvimento da cidadania, para as relações étnico-raciais e de gênero. Todos estes temas estão dispostos ao longo do programa ou currículo do Ensino Fundamental - tanto nos Anos Iniciais quanto nos Anos Finais.

Exemplificamos essas abordagens através de algumas aplicações:

- Unidade Temática - "Mundo pessoal: meu lugar no mundo”, presente no $1^{\circ}$ Ano, cujos objetos de conhecimento apontam para "as diferentes formas de organização da família e da comunidade: os vínculos pessoais e as relações de amizade”.

- Indicamos como orientações metodológicas:

- Organizações familiares diversas, trabalhadas a partir da percepção e das experiências da história dos estudantes, reconhecendo as diversidades presentes no estado de Santa Catarina.

- Datas significativas da família, da escola e da comunidade, respeitando as diferentes organizações familiares e a diversidade.

- Temporalidades:

Familiar: biografias e autobiografias, história do nome, árvore familiar. Ancestralidades: biológica, cultural, social (brincadeiras de ontem e de hoje, jogos, vestuário, alimentação, linguagem) que compõem o mundo do estudante; Fases da vida (percepção de passado, presente e possibilidades de futuro); Percepção da rotina pessoal. [...] - Experimentar diferentes configurações de organização de espaço físico, aproveitando os diferentes lugares da escola como possibilidade educativa e de socialização com pessoas diferentes (SANTA CATARINA, 2019, pp. 446, versão on line).

Como é possível observar, o texto apresentado (e que se encontra na quarta coluna do quadro apresentado no documento original) procura apresentar alguns desdobramentos a partir do que está posto na BNCC. Assim, quando o objeto do conhecimento é descrito como “As diferentes formas de organização da família e da comunidade: os vínculos pessoais e as relações de amizade”, optamos por enfatizar a relevância de reconhecer também as organizações familiares em sua diversidade.

Aplicações com os Anos Finais:

- Para a Unidade Temática: “Os processos de independências nas Américas e Objeto de conhecimento. Para a tutela da população indígena, a escravidão dos negros e a tutela dos egressos da escravidão” foram apontados os seguintes “conteúdos”: 
Povos escravizados no final do período colonial: indígenas e africanos (relações de poder, concentração e expropriação material, processos de resistência, violências, preconceitos, estereótipos e permanências). Destacam-se esses processos em Santa Catarina (SANTA CATARINA, 2019, p. 465, versão online).

Outros exemplos:

- Unidade temática: “A História Recente”, em que constam como objetos de conhecimento:

- “Os conflitos do século XXI e a questão do terrorismo”;

- "Pluralidades e diversidades identitárias na atualidade”;

- “As pautas dos povos indígenas no século XXI e suas formas de inserção no debate local, regional, nacional e internacional”.

Considerando a relevância de compreender a História como processo de estudo para a compreensão e o debate sobre temas do presente, ficaram estabelecidos como conteúdos temáticas tais como:

[...] Processos de globalização e os conflitos do século XXI. Movimentos Sociais: A pauta dos Direitos Humanos: Marchas, movimentos LGBTQIA+, Movimento Negro, Luta pela Terra, Luta pela Moradia, Lutas dos Povos Tradicionais, Direitos da Mulher, direitos dos idosos, direitos da criança e adolescente e de pessoas com deficiência. O papel dos coletivos: Direitos e Movimentos dos Povos Indígenas na atualidade em Santa Catarina; Juventudes em Santa Catarina e no Brasil: movimentos estudantis, "Passe Livre”, Ocupações de escolas; e populações quilombolas. Desmobilização dos movimentos sociais. (SANTA CATARINA, 2019, pp. 474, versão on line).

Os exemplos listados procuram ilustrar as preocupações presentes no texto, aqui já apresentadas: a questão da diversidade, a inserção de temáticas a respeito da História de Santa Catarina e sua relação com a "História Geral e do Brasil e importância de relacionar passadopresente para o estudo e compreensão da História. Como procuramos apontar, essas questões são caraterísticas importantes do texto e foram contempladas por conta da compreensão de todo o grupo a respeito do currículo que estava sendo escrito no processo. Ou seja, entendendo que partíamos de uma BNCC cujo estudo da História se mostrava linear, a alternativa possível foi construir alternativas para essa linearidade, tornando-a mais dinâmica nas idas e vindas ao passado. Procuramos pensar que o encadeamento de fatos apresentados, especialmente do $6^{\circ}$ ao $9^{\circ}$ ano, não deveria ser interpretado simplesmente como o estudo do passado fechado em si mesmo; ao contrário. Daí a referência no texto, sempre que possível, a ações de estudo toda vez que o passado de alguma forma esteja conectado com o presente ou ajude a compreender questões com que nos ocupamos.

\section{Considerações finais}


Contar a história de um trabalho, ainda mais um trabalho feito com tantas mãos, é uma tarefa nada simples. Como assumimos logo no começo deste texto, muitas lacunas podem ter ocorrido pelo caminho. Mas não é este o maior risco do trabalho que nos propusemos a fazer aqui; revisitar um texto escrito é sempre achar coisas que poderiam ter sido feitas de modo diferente. Difícil também é medir possíveis erros. Mas, longe de ser uma defesa do trabalho feito, ou até um acerto de contas com ele, neste artigo buscamos trazer para o debate um longo e complexo processo de escolhas. Decisões, tanto políticas quanto pessoais, e de grupo! E isto foi feito para que o texto de História continuasse a ser construído no dia a dia dos espaços escolares.

Muitas perguntas feitas ao longo do artigo só poderão ser respondidas com o tempo e a experiência. Poderá a ideia de formação integral e de atenção ao percurso formativo ser respeitada considerando o formato das competências e das habilidades indicadas na BNCC? Eis uma pergunta que muitos/as de nós se fizeram no processo de redação do texto (e ainda nos fazemos), sobretudo diante das dúvidas sobre quais, sobre o porquê de ainda não termos visualizado como se dará a vivência desse currículo nos espaços escolares. Ainda que não se tenha encontrado resposta para a questão, registramos o fato de que é necessário pensar não apenas sobre o que se ensina, mas também sobre como e por que ensinar o que ensinamos! É igualmente necessário refletir a respeito de conceitos como competência e habilidade, tão ressaltados nos textos curriculares, mas ainda pouco compreendidos em sua prática.

Encerramos o presente trabalho com a mesma preocupação expressa no texto introdutório do componente do Currículo Base (apesar de amplamente problematizado pelos professores e professoras de História): compreender este texto em seus limites e possibilidades é fundamental para a existência da História como disciplina escolar!

\section{Referências bibliográficas}

ABUD, Katia. Currículos de História e políticas públicas: os programas de História do Brasil na escola secundária. In: BITTERCOURT, Circe. O saber Histórico na sala de aula. Editora contexto, 2006, p. 28-41.

BRASIL. Base Nacional Comum Curricular. 2018.

CAIMI, Flávia Eloisa. A História na Base Nacional Comum Curricular. Revista do Lhiste, Porto Alegre. n. 4, v. 3, jan./jun. 2016.

LAVILLE, Christian. A guerra das narrativas: debates e ilusões em torno do ensino de história. Revista Brasileira de História. São Paulo, v. 19, n. 38, p. 125-138. 1999.

SANTA CATARINA. Currículo Base da Educação Infantil e do Ensino Fundamental do Território Catarinense. 2019. 


\begin{abstract}
' As Fundações Lemann e Reúna, juntamente com os Institutos Airton Senna e Natura fizeram parte do Movimento Brasil Pró BNCC e contribuíram para a organização e composição do texto da BNCC.

ii Participaram do $1^{\circ}$ Seminário os/as seguintes profissionais: Angela Maria Nalevaia Roskamp; Arnaldo Haas Junior; Aurélio dos Santos Souza; Camila Nehring Belo; Cintia Becker Cordeiro; Cintia de Andrade; Deivis Adriano Hinsching; Fabiolla Falconi Vieira; Jeanine Rodermel; Jomara de Liz; Jorge Luiz Buerger; José Francisco Woehl; José Wilson do Prado; Jucelia Barcelos Martins; Luciane Danelli Barragan; Lucélia de Ataide; Lucimara Ávila Isidoro; Moacir Lourenço do Santos; Maria Aparecida Rieth; Marilei das Graças Goulart Almeida; Mário Sérgio Stramosk; Marivânia Ferreira; Marli Aparecida Mesquita Rossetto; Onilse Bastos da Silva; Patrícia Teixeira; Rangel de Oliveira Medeiros; Raquel Mara Martins Weiss; Rita Zanchet Couto; Rodrigo Pinheiro; Samuel da Silva Hipólito; Silvane Terezinha da Silva Prestes de Oliveira; Silvio Martins; Simão Henrique Jakobowski; Terezinha de Jesus Andrade Clemente e Valdeci José de Oliveira.
\end{abstract}

Recebido em 30/09/2019.

Aceito em 10/11/2019. 